\title{
Criss-cross hemostatic suture in nephron sparing open surgery
}

Alchiede Simonato ${ }^{1}$, Pinelli Mirko, Gabriele Tulone, Marco VELLA ${ }^{1}$, Rosa Giaimo, Piero Mannone ${ }^{1}$, Davide Baiamonte, Nicola Pavan

1 University of Palermo

Funding: The author(s) received no specific funding for this work.

Potential competing interests: The author(s) declared that no potential competing interests exist.

\begin{abstract}
Surgery is the curative treatment for localized Renal Cancer Carcinoma (RCC). Nephron sparing surgery is the recommended treatment modality in patients with T1 tumors based on oncological and functional outcomes [1]. Patients with stage Tla renal cancer who have undergone conservative surgery have demonstrated better survival and functional outcomes [2]. Renorrhaphy and resection technique are important for the preservation of the renal function. To date no technique is clearly preferable, and the choice can be made based on preference and experience of the surgeon [5]. The criss-cross technique guarantees excellent haemostasis by limiting the insult on healthy renal parenchyma.
\end{abstract}

\section{Introduction}

Surgery is the curative treatment for localized Renal Cancer Carcinoma (RCC). Nephron sparing surgery is the recommended treatment modality in patients with T1 tumors based on oncological and functional outcomes [1]. Patients with stage Tla renal cancer who have undergone conservative surgery have demonstrated better survival and functional outcomes [2]. Regardless of the surgical technique, the transperitoneal approach for nephron sparing surgery may increase postoperative adhesions and complications. The retro-peritoneal approach offers many advantages, including direct access to the kidney and renal hilum, reduction of the operative time, and minimization of the dissection during surgery [3].

Despite the time to ischemia remains a debated factor, especially when 25 minutes of ischemia are exceeded, the preservation of healthy renal parenchyma is of utmost significance for the prevention of acute kidney injury (AKI) and for the maintenance of a long-term renal function (RF). Healthy parenchyma volume loss (HPVL) is minimized using enucleation techniques [4]. The type of renorrhaphy and the techniques of resection of the tumor are important for the preservation of the renal function. No technique is clearly preferable, and the choice can be made based on preference and experience of the surgeon [5]. 


\section{Methods}

A 65-year-old male (Body mass index: $18 \mathrm{~kg} / \mathrm{m} 2$ ) was referred to our clinic with a renal mass (PADUA score 6) of the left kidney incidentally discovered following a chest-abdomen CT performed for lobar pneumonia. The renal exophytic tumour was $3.6 \mathrm{~cm}$ in the upper pole with a 6,6 cm2 Contact Surface Area (CSA). Access to the kidney was guaranteed through an incision in the flank above the eleventh rib. After the dissection of the external oblique muscle, the periosteal surface was exposed, and the costal margin was isolated. The Doyen's unglued rib was inserted below the lower costal margin following a subperiosteal plane and pushed towards the apex. The rib was sectioned as posteriorly as possible with the costotome.

Through a retro-peritoneal approach the kidney was extensively mobilized to facilitate access to the tumor.

Renal capsule incision was performed with electric scalpel outlining the resection margins. Before ischemia, $100 \mathrm{ml}$ of intravenous mannitol was administered.

A tourniquet (Rumel) was used for clamping the main artery. A concomitant renal vein clamping was rarely performed in cases of difficult isolation of the vascular peduncle. Enucleoresection was preferred to classical partial nephrectomy.

After the removal of the lesion, no electrical coagulation was used over the resected area. Major visible collecting system defects were sutured using a 2-0 poly-filament ( $22 \mathrm{~mm}$ needle) .

The inner renorrhaphy was performed with one or more continuous 2.0 poly-filament sutures ( $22 \mathrm{~mm}$ needle) to create a layer above the entire resected area.

One or more sutures ( $26 \mathrm{~mm}$ needle) was used for cortical renorrhaphy (Figure 1 ). The needle was passed through the cortical parenchyma, from the capsule to the resection bed, under the continuous sutures previously placed on the medullary defect. 3 interrupted 2-0 polyfilament threads ( $31 \mathrm{~mm}$ needle) placed every $1 \mathrm{~cm}$ of distance were passed from the outside to the inside margins of the kidney. Tabotamp was applied to the resection bed to improve the hemostasis. A fibrin glue (tisseel) was added together with 3 other tabotamp rolls. At the end, the net was tied and an additional layer of tabotamp and glue was applied on the cortical margins at the end of renorrhaphy.

\section{Results}

Operative time was 130 min with negligible blood loss (20ml). The warm ischemia time (WIT) was 17 mins. The surgery was completed successfully without intraoperative complications. Patient was_mobilized on the first postoperative day. On the second day the drainage was removed. The postoperative course was uneventful, and the patient was discharged home on postoperative day 4 without a catheter and in good clinical condition. Histopathological examination of the specimen reported a 4,2 cm papillary renal cells type 1 ( $\mathrm{pTla}$ ) grade 2 Fuhrman tumour with negative margins. After 3 months, the postoperative eGFR 
was 87 ml\min with a PCE $9 \%$.

In our experience, all patients treated with the criss-cross renorrhaphy technique achieved similar results (table 1-2). Despite a lot of time being dedicated to the renorrhaphy phase, in all cases treated with the criss-cross technique the WIT was less than 25 minutes with a median WIT of 17 minutes (IQR WIT17 mins).

\section{Conclusion}

The criss-cross technique guarantees excellent haemostasis by limiting the insult on healthy renal parenchyma. The goal is to create a medullary net with the sutures. The passage of the needle from the resection bed towards the cortical portion (from the inside to the outside) will help to create a multidirectional haemostasis reducing the excessive tension of the standard renorrhaphy.

\section{References}

[1]. Ljungberg B, Albiges L, Abu-Ghanem Y, Bensalah K, Dabestani S, Fernández-Pello S, Giles RH, Hofmann F, Hora M, Kuczyk MA, Kuusk T, Lam TB, Marconi L, Merseburger AS, Powles T, Staehler M, Tahbaz R, Volpe A, Bex A. European Association of Urology Guidelines on Renal Cell Carcinoma: The 2019 Update. Eur Urol. 2019 May;75(5):799-810. doi: 10.1016/j.eururo.2019.02.011. Epub 2019 Feb 23. PMID: 30803729.

[2]. Thompson RH, Boorjian SA, Lohse CM, Leibovich BC, Kwon ED, Cheville JC, et al. Radical nephrectomy for pTla renal masses may be associated with decreased overall survival compared with partial nephrectomy. J Urol. 2008;179:468-71. discussion 72-3.

[3]. Pattaras JG, Moore RG, Landman J, et al. Incidence of postoperative adhesion formation after transperitoneal genitourinary laparoscopic surgery. Urology. 20032;59:37-41.

[4]. Marconi L, Desai MM, Ficarra V, et al. Renal Preservation and Partial Nephrectomy: Patient and Surgical Factors. Eur Urol Focus. 2016;2:589-600.

[5]. Castilla EA, Liou LS, Abrahams NA, et al. Prognostic importance of resection margin width after nephron-sparing surgery for renal cell carcinoma. Urology 2002;60:993-7. 